\title{
KEMULIAAN SEORANG GURU DALAM PERSPEKTIF AL GHAZALI
}

\author{
Lia Istifhama ${ }^{1}$ \\ e-mail: liaistifhamah@gmail.com
}

STAI TARUNA SURABAYA

\begin{abstract}
Abstrak: Menarik menyimak pemikiran sang Hujjatul Islam (حُجَُّ الِْسنْاِد), Imam Al Ghazali, mengenai pendidikan. Ghazali menaruh perhatian yang besar akan penyebarluasan ilmu dan pendidikan, karena beliau yakin bahwa pendidikan adalah sebagai sarana untuk menyebarluaskan keutamaan, membersihkan jiwa dan sebagai media untuk mendekatkan manusia kepada Allah. Dengan itulah, pendidikan menurut Al-Ghazali adalah suatu ibadah dan sarana kemashlahatan untuk membina umat. Oleh sebab itu, disamping meningkatkan karirnya sebagai filosof dan ahli agama, Ghazali juga sebagai reformer masyarakat. Hal ini menjadikan Al-Ghazali merupakan salah satu tokoh fenomenal yang memberi concern pendidikan, seperti halnya Plato, J.J Rousseau dan Pestalozzi bagi dunia Barat.
\end{abstract}

Kata Kunci: Kemuliaan, Guru, Al Ghozali

\section{A. PENDAHULUAN}

Al-Ghazali الْغَزَا لِي yang nama lengkapnya Abu Hamid Muhammad bin Muhammad Al-Ghazâlî At-Tusi An Naysaburi, lahir di Ghazlah, suatu kota di Tus Khurasan, Iran, pada tahun $450 \mathrm{H}(1058 \mathrm{M})^{2}$, tiga tahun setelah dinasti Salajiqah mengambil alih Daulah Abbasiyah.

Sejak muda, Al-Ghazâlî sangat antusias terhadap ilmu pengetahuan. Ia pertamatama belajar bahasa Arab dan fiqh di kota Tus kepada seorang 'alim yang bernama ashShaikh Ah\{mad ibn Muhammad ar-Radakani. Al-Ghazâlî kemudian pergi ke kota Jurjan untuk belajar dasar-dasar Usul Fiqih dan pergi ke Naysaburi untuk melanjutkan rihlah ilmiahnya. Di kota ini, Al-Ghazâlî belajar kepada Imam al-Haramayn Abd alMalik al-Juwayni, hingga tahun $478 \mathrm{H}^{3}$. Al- Juwaini kemudian menganjurkan pada Wazir Nizam al Mulk (pengarang kitab siyasat-nameh) untuk mengangkat Al-Ghazâlî

\footnotetext{
${ }^{1}$ Dosen Tetap STAI Taruna Surabaya

2 Nur Chamid, Jejak Langkah Sejarah Pemikiran Ekonomi Islam (Yogyakarta: Pustaka Pelajar, 2010), 218.

${ }^{3}$ Euis Amalia, Sejarah Pemikiran Ekonomi; Islam, Dari Masa Klasik Hingga Kontemporer (Jakarta:

Pustaka Asatruss, cet.I, 2005), 121.
} 
sebagai profesor filsafat di sekolah Nizamiyyah di pusat Baghdad ${ }^{4}$, pada tahun $483 \mathrm{H}$. Ia pun mampu mengembannya dengan berhasil, sehingga para ilmuwan menjadikannya sebagai referensi utama dan kemudian menjadi rektor di Nizamiyyah ${ }^{5}$.

Kemudian, pada 488 H (1095 M), Al Ghazâlî meninggalkan Baghdad dan pergi ke Syiria selama 2 tahun dan selanjutnya pindah ke baitul maqdis, Palestina. Setelah menunaikan ibadah haji dan menetap beberapa waktu di kota Iskandariah, Mesir, Al Ghazâlî kembali ke tempat Tus pada tahun 499 H (1105 M) untuk berkhalwat. Selama 12 tahun proses pengasingannya keilmuannya, ia banyak menghasilkan berbagai karyanya yang terkenal, seperti Ihya 'Ulum al-Din, Tahafut al-Falasifah, Maqasid alFalasifah, al-Munqizh min al-Dalal, Ayyuha al-Walad, Mizan al-'Amal, dan sebagainya'. Menurut 'Abdurrahman Badawi, al-Ghazâlî telah menghasilkan karya mencapai 457 buah, yang meliputi berbagai disiplin ilmu, seperti logika, filsafat, moral, tafsir, fiqh, ilmu al-Qur'an, tasawuf, politik, administrasi, dan ekonomi ${ }^{7}$. Karya monumentalya, Ihya 'Ulum al-Din, bahkan, diadopsi oleh St. Thomas Aquinus dalam Summa Theologica. Tokoh lain yang "mengadopsi” pemikirannya, diantaranya adalah Raymond Martin dan Pascal. Karya-karya al-Ghazâlî sendiri, telah diterjemahkan dalam bahasa Latin, Spanyol, Yahudi, Perancis, Jerman, Inggris, dan sebagainya. Al-Ghazâlî menghabiskan waktunya untuk ilmu pengetahuan hingga meninggal dunia pada 14 Jumadil Akhir $505 \mathrm{H}$.

\section{B. Kemuliaan Seorang Guru Menurut Al-Ghazali}

Al-Ghazali termasuk ke dalam kelompok sufistik yang banyak menaruh perhatiannya yang besar terhadap pendidikan, karena pendidikanlah yang banyak menentukan corak kehidupan suatu bangsa dan pemikirannya. Menurut Arifin (Guru besar dalam bidang pendidikan), mengatakan bila dipandang dari segi filosofis, AlGhazali adalah penganut faham idealisme yang konsekuen terhadap agama sebagai dasar pandangannya. Dalam masalah pendidikan, Al-Ghazali lebih cenderung berpaham empirisme. Hal ini antara lain disebabkan karena ia sangat menekankan pengaruh

\footnotetext{
${ }^{4}$ Faruqi (al), Atlas Budaya: Menjelajah Khazanah Peradaban Gemilang Islam (Bandung: Mizan, 1986), 330

${ }^{5}$ Amalia, Sejarah Pemikiran Ekonomi Islam, 122.

${ }^{6}$ Chamid, Jejak Langkah Sejarah Pemikiran Ekonomi Islam, 219

${ }^{7}$ Al-Ghazâlî, Mutiara Ihya' Ulumuddin: Ringkasan yang Ditulis Sendiri Oleh Sang Hujjatul Islam. Terj. Irwan Kurniawan (Bandung: Mizan, 2008), 11
} 
pendidikan terhadap peserta didik. Menurutnya, seorang anak tergantung kepada orang tua dan siapa yang mendidiknya. Hati seorang anak itu bersih, murni laksana permata yang amat berharga, sederhana dan bersih dari gambaran apapun. ${ }^{8}$ Al-Ghazali mengatakan, jika anak menerima ajaran dan kebiasaan hidup yang baik, maka anak itu menjadi baik. Sebaliknya, jika anak itu dibiasakan kepada hal-hal yang jahat, maka anak itu akan berakhlak jelek.

Pemikiran pendidikan Al-Ghazali dapat dilihat dari dua segi, yaitu: teoritis dan praktis. Sisi teoritis dari pemikirannya ialah terfokus pada konsep pengetahuan, yang mana di sini Al-Ghazali menawarkan ide-ide yang cukup mendetail tentang bagaimana manusia memperoleh pengetahuan, nilai ilmu pengetahuan dan kemudian menawarkan klasifikasi ilmu pengetahuan. Dalam sisi ini, Al-Ghazali melihat ilmu pengetahuan dari berbagai sudut; nilai intrinsiknya, nilai etisnya dan nilai sosialnya.

Sedangkan segi praktis dari pemikirannya terpusat pada pola hubungan guru dengan murid. Diskusinya tentang guru dan murid mencakup berbagai kewajiban bagi kedua belah pihak, yang menurut Al-Ghazali akan menjamin tercapainya tujuan pendidikan Islam. Bagi Al-Ghazali, tujuan akhir pendidikan adalah hari akhirat, sebagaimana halnya hari akhirat juga merupakan tujuan akhir dari kehidupan umat manusia. Konsekuensinya adalah bahwa keseluruhan proses pendidikan harus menuju tercapainya tujuan akhir. ${ }^{9}$

Adapun tujuan pendidikan menurut Al-Ghazali, yaitu:

1) Insan purna yang bertujuan mendekatkan diri kepada Allah SWT, bukan untuk mencari kedudukan, kemegahan dan kegagahan atau mendapatkan kedudukan yang menghasilkan uang. Karena jika tujuan pendidikan diarahkan bukan pada mendekatkan diri kepada Allah, akan dapat menimbulkan kedengkian, kebencian dan permusuhan. Hal ini mencerminkan sikap zuhud Al-Ghazali terhadap dunia, merasa qan'aah (merasa cukup dengan yang ada) dan banyak memikirkan kehidupan akhirat dari pada kehidupan dunia.

2) Sarana yang bertujuan mendapatkan kebahagiaan hidup dunia dan akhirat. Dalam hal ini, Al-Ghazali memandang bahwa dunia ini bukan merupakan hal pokok, tidak abadi dan akan rusak, sedangkan maut dapat memutuskan kenikmatan setiap saat.

\footnotetext{
8 Abuddin Nata, Filsafat Pendidikan Islam (Jakarta: Logos Wacana Ilmu, 1997), 161.

9 Hasan Asari, Nukilan Pemikiran Islam Klasik: Gagasan Pendidikan Al-Ghazali (Yogyakarta: Tiara Wacana Yogya, 1999), 4.
} 
Tujuan pendidikan Al-Ghazali tidak sama sekali menistakan dunia, melainkan dunia ini hanya sebagai alat. ${ }^{10}$

Al-Ghazali mempergunakan istilah guru dengan berbagai kata, al-muallim (guru), al-mudarris (pendidik), dan al-walid (orang tua). ${ }^{11}$ Menurutnya, guru adalah seseorang yang bertanggung jawab atas pendidikan dan pengajaran, serta bertugas untuk menyempurnakan, mensucikan dan menjernihkan serta membimbing anak didiknya untuk mendekatkan diri kepada Allah SWT. Pandanganya ini merupakan wujud dari pribadi sufinya.

Sebagai bahan dialog, jika Al-Ghazali memiliki paradigma sufistik, maka Zakiah Darajdat memiliki pandangan dalam segi psikologis. Dalam hal ini, seorang pendidik adalah sosok yang memiliki suatu kepribadian. Dimana kepribadiannya itu dapat memberikan motivasi pada anak untuk meningkatkan belajarnya, karena dengan kepribadian terpadu, guru tampak stabil, optimis dan menyenangkan, sehingga ia dapat memikat anak didiknya, karena setiap anak merasa diterima dan disayangi oleh guru, betapapun sikap, adap dan tingkah lakunya.

Dalam pandangannya, Al-Ghazali sering mengemukakan pendapatnya tentang ketinggian derajat dan kedudukan para guru ini dalam beberapa tempat dikitabnya, Ihya 'Ulum al-Din. Misalnya beliau berkata:

"Dan tidaklah tersembunyi bahwa ilmu agama ialah memahami jalan akhirat, yang dapat diketahui dengan kesempurnaan akal dan kebersihan kecerdikan. Akal adalah yang termulia dari sifat-sifat insan sebagaimana akan diterangkan nanti. Karena dengan akal, manusia menerima amanah Allah. Dan dengan akal akan sampai ke sisi Allah SWT. Adapun tentang umum kegunaannya, maka tak diragukan lagi, karena kegunaan dan keberhasilannya ialah kebahagiaan akhirat. Adapun kemuliaan tempat, maka bagaimana tersembunyi? Guru itu berpengaruh dalam hati dan jiwa manusia. Yang termulia di atas bumi, ialah jenis manusia. Yang termulia dari bagian tubuh manusia ialah hatinya. Guru itu bekerja menyempurnakan, membersihkan, mensucikan dan membawakan hati itu mendekati Allah Azza wa Jalla. Mengajarkan ilmu itu dari satu segi adalah ibadah kepada Allah Ta'ala dan dari segi yang lain adalah menjadi khalifah Allah Ta'ala. Dan itu adalah yang termulia menjadi

10 Fathiyah Hasan Sulaiman, Sistem Pendidikan Versi Al-Ghazali (Bandung: P.T. Al-Ma'arif, 1993), 24.

11 Zainuddin, Seluk Beluk Pendidikan dari Al-Ghazali (Jakarta: Bumi Aksara, 1991), 50. 
khalifah Allah. Bahwa Allah telah membuka pada hati orang berilmu, akan pengetahuan yang menjadi sifatNya yang teristimewa, maka dia adalah seperti penjaga gudang terhadap barang gudangannya yang termulia. Kemudian diizinkan berbelanja dengan barang itu untuk siapa saja yang membutuhkannya." 12

Al-Ghazali menyamakan keberhasilan ilmu dengan terhimpunnya harta kekayaan. Artinya, baik orang yang berhasil memperoleh ilmu maupun orang berhasil mengumpulkan harta kekayaan berada di dalam salah satu dari empat jenis berikut ini:

1. Orang yang berhasil memperoleh harta kekayaan atau ilmu lalu disimpannya, tidak dimanfaatkan untuk kepentingan apapun juga.

2. Orang yang menyimpan harta kekayaan atau ilmu sebanyak-banyaknya untuk dimanfaatkan sendiri, sehingga ia tidak perlu untuk meminta-minta.

3. Orang yang berhasil memperoleh ilmu atau harta kekayaan untuk dimanfaatkan atau dinafkahkan sendiri.

4. Orang yang berhasil memperoleh ilmu atau harta kekayaan untuk dinafkahkan atau dengan menyebarkan ilmunya untuk menolong orang lain. ${ }^{13}$

Al-Ghazali menganggap orang termasuk dalam jenis keempat adalah orang yang paling mulia. Karena, orang yang berilmu dan mengajarkan ilmunya hingga orang lain dapat memanfaatkannya diibaratkan sebagai matahari yang memancarkan sinarnya kepada makhluk lain, sedangkan dirinya sendiri tetap bersinar dan juga sebagai minyak kasturi yang menyebarkan parfum kepada sekitarnya, sedangkan dia sendiri masih tetap mempunyai bau yang harum itu.

Seterusnya ia memuji orang yang berilmu sekaligus yang mengajarkannya, dalam perkataannya yang termaktub di Ihya 'Ulum al-Din:

"Maka seperti itu pulalah dengan ilmu pengetahuan, dapat disimpan seperti menyimpan harta benda. Bagi ilmu pengetahuan ada keadaan mencari, berusaha dan keadaan menghasilkan yang tidak memerlukan lagi kepada bertanya. Keadaan meneliti (istibshar), yaitu berpikir mencari yang baru dan mengambil faidah daripadanya. Dan keadaan memberi sinar cemerlang kepada orang lain. Dan inilah keadaan yang semulia-mulianya. Maka barang siapa berilmu, beramal dan mengajar, maka dialah yang disebut orang besar. Dia laksana matahari yang menyinarkan

\footnotetext{
Al-Ghazali, Ihya' Ulumuddin, Cet VI. Terj., Ismail Yakub (Semarang: C.V. Faizan, 1979), 77. Sulaiman, Sistem Pendidikan, 43.
} 
cahayanya kepada lainnya dan menyinarkan pula kepada dirinya sendiri. Dia laksana kesturi yang membawa keharuman kepada lainnya dan dia sendiripun harum." 14

Masih dalam kitab yang sama, ia pun berkata sebagai berikut:

"Orang yang berilmu dan tidak beramal menurut ilmunya, adalah seumpama suatu daftar yang memberi faidah kepada lainnya dan dia sendiri kosong dari ilmu pengetahuan. Dan seumpama batu pengasah, menajamkan lainnya dan dia sendiri tidak dapat memotong. Atau seumpama jarum penjahit yang dapat menyediakan pakaian untuk lainnya dan dia sendiri telanjang. Atau seumpama sumbu lampu yang dapat menerangi lainnya dan dia sendiri terbakar, sebagaimana kata pantun: "Dia adalah laksana sumbu lampu yang dipasang, memberi cahaya kepada orang lain, dia sendiri terbakar menyala." 15

Dari beberapa perkataan Al-Ghazali di atas, dapat dipahami bahwa profesi keguruan merupakan profesi yang paling mulia dan paling agung dibandingkan dengan profesi yang lain. Dengan profesinya itu seorang guru menjadi perantara antara manusia dalam hal ini murid, dengan penciptanya yaitu Allah SWT.

Sementara dalam salah satu kitab lainnya, Ayyuhā al-Walad fì Nasīhati alMuta 'allimīn wa Maw 'izatihim Liya 'lamū wa Yumayyizū 'Ilman Nāfi 'an min Gayrihi, ia menerangkan beberapa faktor yang menentukan keberhasilan dalam proses belajar, yang termasuk di dalamnya adalah peran guru:

1. Motivasi. Motivasi merupakan salah satu faktor internal yang sangat penting dalam menentukan keberhasilan siswa dalam belajar. Hal ini diyakini oleh AlGhazali dalam ungkapannya: "Jika motivasinya adalah untuk memperoleh harta benda dan kedudukan serta untuk membanggakan diri sesama teman-teman, maka sungguh kamu akan celaka. Tetapi jika niat kamu dalam belajar adalah untuk menghidupkan syariat Nabi Muhammad dan untuk membersihkan akhlakmu serta untuk menghilangkan nafsu ammarah, maka sungguh kamu akan beruntung." 16

\footnotetext{
14 Ghazali, Ihya' Ulumuddin, 44.

${ }^{15}$ Al-Ghazali, Ayyuhā al-Walad fì Nasīhati al-Muta 'allimīn wa Maw 'izatihim Liya 'lamū wa Yumayyizū

'Ilman Näfi'an min Gayrihi (Jakarta: al-Haramain Jaya, t.t), 212.

${ }^{16}$ Ibid., 6.
} 
2. Guru. Guru yang selalu menunjukkan sikap dan perilaku yang baik dan profesional dalam menjalankan tugasnya akan berdampak baik bagi perkembangan siswa dalam belajar. Untuk itu, guru yang diingini oleh Imam Al-Ghazali adalah guru yang mampu membuang akhlak tercela dari dalam diri anak didik dengan tarbiyah dan menggantinya dengan akhlak yang baik. Adapun syarat kualitatif yang harus dimiliki oleh guru antara lain, pintar (alim), serta tidak tergiur oleh keindahan dunia dan kehormatan jabatan. Di samping itu, seorang guru harus menjadikan akhlak-akhlak yang baik sebagai landasan perilaku kesehariannya seperti sabar, membaca salawat, syukur, tawakkal, yakin, qana'ah, ketentraman jiwa, lemah lembut, rendah hati, ilmu, jujur, malu, menepati janji, berwibawa, tenang, tidak terburu-buru, dan lain-lain. ${ }^{17}$

3. Kurikulum. Kurikulum yang dikehendaki oleh Imam Al-Ghazali adalah kurikulum yang mampu menjadikan anak didik untuk taat beribadah kepada Allah, sesuai dengan perkataannya: "Anakku, inti dari ilmu adalah ketika kamu mengetahui apa itu taat dan ibadah. Ketahuilah! Ketaatan dan ibadah adalah mengikuti Allah dalam hal perintah dan larangan, dengan ucapan sekaligus tindakan.”18

4. Sikap. Sikap yang dimiliki siswa terhadap guru dan/atau mata pelajaran yang disampaikan juga tak kalah pentingnya dalam menentukan keberhasilan siswa dalam belajar. Karena itu, Imam Al-Ghazali menekankan agar siswa menghormati seorang guru baik secara batin atau lahir. Aktualisasi dari penghormatan lahiriyah, misalnya dijelaskan oleh al-Ghazali, dengan tidak mendebat dan banyak argumentasi terhadap penjelasan guru, tidak menggelar sajadah di hadapannya kecuali pada waktu shalat, itupun jika sudah selesai harus cepat mengangkatnya, dan mengerjakan apa saja yang diperintahkan oleh gurunya sebatas kemampuannya. Sedangkan aktualisasi penghormatan batiniyah dengan tidak mengingkari apa yang ia dengar dan terima darinya, baik dalam ucapan maupun tindakan, agar ia tidak dicap sebagai hipokrit, jika memang tidak mampu berbuat yang demikian, ia sebaiknya tidak berinteraksi dengan guru tersebut sehingga ia rasa mampu menerimanya secara lahir dan batin. ${ }^{19}$

\footnotetext{
${ }^{17}$ Ibid., 13-14.

${ }^{18}$ Ibid., 9.

${ }^{19}$ Ibid., 14-15.
} 
5. Kesucian Hati. Hati yang bersih dari sifat-sifat yang tercela juga merupakan faktor yang mempengaruhi keberhasilan siswa dalam belajar. Hal ini diakui oleh Imam Al-Ghazali dengan menginginkan siswa agar ikhlas dan tawakkal, serta memilih kefakiran daripada kekayaan harta dalam belajar dan menuntut ilmu. Sesuai dengan ungkapannya: "Ketahuilah ikhlas adalah kamu menempatan segenap amalan hanya demi Allah semata, dengan mengabaikan segala pujian manusia. Dan pujian manusia itu kemudian melahirkan sifat riy $\bar{a}$ '. Maka cara menghindari dari sifat riya' adalah dengan melihat mereka yang memuji sebagai sekedar mengolok-olok atau memandang mereka sebagai benda mati yang tidak punya kekuatan apa-apa."20

6. Lingkungan Sosial. Lingkungan sosial yang dimaksud di sini adalah lingkungan eksternal yang mengitari siswa baik terdiri dari teman bergaul dan atau masyarakat di sekitarnya. Lingkungan sosial tersebut sangat berpengaruh dan menjadi faktor akan keberhasilan siswa dalam belajar. Untuk itu Imam Al-Ghazali mengingatkan agar jangan bergaul dengan orang-orang yang memiliki perangai yang kurang baik. Hal ini sesuai dengan perkataannya: "seorang murid juga harus menjaga diri dari berteman dengan rekan yang tidak baik tingkah lakunya demi membatasi pengaruh setan berwujud jin dan manusia dari piring hatinya sehingga ia bersih dari kotoran setan." 21

\section{PENUTUP}

Pemikiran sufistik Al-Ghazali telah menempatkan seorang guru sebagai sosok yang mulia namun di satu sisi memiliki tanggung jawab yang besar dalam mengemban tugasnya. Guru sangat berperan menentukan akhlak anak didik dan ilmu yang yang baik sehingga mampu mendekatkan anak didik kepada Allah SWT.

Sosok guru menurut perspektif Al-Ghazali selaras dengan tujuan pendidikan dimana bertujuan mendekatkan diri kepada Allah SWT serta mencari kebahagiaan hidup dunia dan akhirat. Untuk mencapai keberhasilan tujuan tersebut, dibutuhkan peran seorang guru, yang tertulis dalam kitabnya, Ihya 'Ulum al-Din, sebagai sosok yang mulia dan tinggi derajatnya.

\footnotetext{
${ }^{20}$ Ibid., $15-16$.

${ }^{21}$ Ibid., $14-15$.
} 
Jurnal Keislaman, Vol. 2, No. 1, Maret

Dengan begitu, Al-Ghazali pun telah menempatkan profesi keguruan sebagai profesi yang paling mulia dan paling agung dibandingkan dengan profesi yang lain karena seorang guru menjadi perantara antara manusia (dalam hal ini murid), dengan penciptanya yaitu Allah SWT. 


\section{DAFTAR PUSTAKA}

Amalia, Euis. Sejarah Pemikiran Ekonomi; Islam, Dari Masa Klasik Hingga Kontemporer. Jakarta: Pustaka Asatruss, cet.I, 2005.

Asari, Hasan. Nukilan Pemikiran Islam Klasik: Gagasan Pendidikan Al-Ghazali. Yogyakarta: Tiara Wacana Yogya, 1999.

Chamid, Nur. Jejak Langkah Sejarah Pemikiran Ekonomi Islam. Yogyakarta: Pustaka Pelajar, 2010.

Faruqi (al). Atlas Budaya: Menjelajah Khazanah Peradaban Gemilang Islam (Bandung: Mizan, 1986), 330

Ghazâlî (al). Ayyuhā al-Walad fì Nasīhati al-Muta 'allimīn wa Maw 'izatihim Liya 'lamū wa Yumayyizù 'Ilman Näfi'an min Gayrihi . Jakarta: al-Haramain Jaya, t.t.

Ghazâlî (al). Ihya' Ulumuddin, Cet VI. Terj., Ismail Yakub. Semarang: C.V. Faizan, 1979.

Ghazâlî (al). Mutiara Ihya' Ulumuddin: Ringkasan yang Ditulis Sendiri Oleh Sang Hujjatul Islam. Terj. Irwan Kurniawan. Bandung: Mizan, 2008.

Nata, Abuddin. Filsafat Pendidikan Islam. Jakarta: Logos Wacana Ilmu, 1997.

Sulaiman, Fathiyah Hasan. Sistem Pendidikan Versi Al-Ghazali. Bandung: P.T. AlMa'arif, 1993.

Zainuddin, Seluk Beluk Pendidikan dari Al-Ghazali. Jakarta: Bumi Aksara, 1991. 